\title{
Outcome of intracerebral cavernoma treated by Gamma Knife radiosurgery based on a double-blind assessment of treatment indication
}

Chiung-Chyi Shen ${ }^{1,2+}$, Ming Hsi Sun ${ }^{1}$, Meng-Yin Yang ${ }^{1}$, Weir-Chiang You ${ }^{3}$, Meei-Ling Sheu ${ }^{4 \dagger}$, Yen-Ju Chen ${ }^{1}$, Ying Ju Chen ${ }^{5}$, Jason Sheehan ${ }^{6}$ and Hung-Chuan Pan ${ }^{7,8^{*}}$ (i)

\begin{abstract}
Background: The benefit and the risk profile of Gamma Knife radiosurgery (GKRS) for intracerebral cavernoma remains incompletely defined in part due to the natural history of low incidence of bleeding and spontaneous regression of this vascular malformation. In this study, we retrieved cases from a prospectively collected database to assess the outcome of intracerebral cavernoma treated with GKRS using a double blinded review process for treatment.

Methods: From 2003 to 2018, there were 94 cases of cavernoma treated by GKRS in the doubly blinded assessments by two experienced neurological and approved for GKRS treatment. All the patients received GKRS with margin dose of 11-12 (Gray) Gy and afterwards were assessed for neurological outcome, radiologic response, and quality of life.

Results: The median age of the patients was 48 (15-85) years with median follow up of 77 (26-180) months post SRS. The mean target volume was $1.93 \pm 3.45 \mathrm{cc}$. In those who has pre-SRS epilepsy, 7 of 16 (43.7\%) achieved seizure freedom (Engel I/II) and 9 of 16 (56.3\%) achieved decreased seizures (Engel III) after SRS. Rebleeding occurred in 2 cases (2.1\%) at 13 and 52 months post SRS. The radiologic assessment demonstrated 20 (21.3\%) cases of decreased cavernoma volume, 69 (73.4\%) were stable, and $5(7.3 \%)$ increased size. Eighty-seven of 94 (92.5\%) cases at the last follow up achieve improvement in their quality of life, but 7 cases (7.4\%) showed a deterioration. In statistical analysis, the effective seizure control class (Engel I/II) was highly correlated with patient harboring a single lesion $(p<0.05)$ and deep seated location of the cavernoma $(p<0.01)$. New neurological deficits were highly correlated with decreased mental $(p<0.001)$ and physical $(p<0.05)$ components of quality of life testing, KPS ( $p<0.001)$, deep seated location $(p<0.01)$, and increased nidus volume $(p<0.05)$. Quality of life deterioration either in physical component $(p<0.01)$, mental component $(p<0.01)$, and KPS $(p<0.05)$ was highly correlated with increased cavernoma volume.
\end{abstract}

Conclusion: Low margin dose GKRS for intracerebral cavernoma offers reasonable seizure control and improved quality of life while conferring a low risk of treatment complications including adverse radiation effect.

*Correspondence: hcpan2003@yahoo.com.tw

${ }^{\dagger}$ The authors Chiung-Chyi Shen and Meei-Ling Sheu contributed equally to this work

${ }^{7}$ Department of Medical Research and Neurosurgery, Taichung Veterans General Hospital, 1650 Taiwan Boulevard Sec.4, Taichung 40705, Taiwan

Full list of author information is available at the end of the article

\section{Background}

Intracerebral cavernoma $(\mathrm{CM})$ are uncommon in the general population, with a prevalence ranging from 0.3 to $0.6 \%$ based on large autopsy series and prospective cohort studies. The increasing incidence of cavernoma is largely due to diagnostic advances with widespread original author(s) and the source, provide a link to the Creative Commons licence, and indicate if changes were made. The images or other third party material in this article are included in the article's Creative Commons licence, unless indicated otherwise in a credit line to the material. If material is not included in the article's Creative Commons licence and your intended use is not permitted by statutory regulation or exceeds the permitted use, you will need to obtain permission directly from the copyright holder. To view a copy of this licence, visit http://creativecommons.org/licenses/by/4.0/. The Creative Commons Public Domain Dedication waiver (http://creativeco mmons.org/publicdomain/zero/1.0/) applies to the data made available in this article, unless otherwise stated in a credit line to the data. 
use of magnetic resonance imaging (MRI) in clinical practice (prevalence 0.4-0.9\%) [1-4]. Individuals with CMs can present with seizures $(23-50 \%$ of cases), headaches $(6-52 \%)$, focal neurological deficits (20$45 \%)$, or hemorrhages (9-56\%) [1, 5-10]. The extent of permanent neurological deficits highly correlates with the number of recurrent hemorrhages, and re-bleeding episodes tend to occur at progressively shorter time intervals [11]. In patients with a symptomatic cavernoma, microsurgery is the best treatment for CM, especially given advances in microsurgical techniques and neuronavigation-guided approaches [12]. For patients with deeper seated or eloquently situated cavernomas, Gamma Knife radiosurgery (GKRS) is considered as an alternative [13-15].

The use of radiosurgery for cavernoma remains controversial especially for the primary goal of reducing the bleeding rate. Some authors have favored radiosurgery for intracranial cavernoma, due to a reduced risk of hemorrhages after a latency period of $2-3$ years [16-18]. But others are less convinced about the benefits of SRS for cavernomas for a variety of reasons. First, the hemorrhage rate, particularly for retrospective series, is not simple to calculate due to the appearance of cavernoma in de novo and referral and treatment biases [19]. Second, the high-risk CM patients are usually selected to undergo surgery after SRS and thus deflate the postSRS hemorrhage rates with time [20]. Ironically, in some reports, SRS itself can also induce de novo CM development [21-23]. Furthermore, the risk of a CM rebleeding is typically high for 2-3 years after the initial hemorrhage and, thereafter, cavernoma re-hemorrhage after SRS appears to be reduced after this period of time [24]. The temporal clustering of hemorrhagic events might give a false impression of how aggressive a lesion will be in the long term. The decline in hemorrhagic events observed after treating CMs with SRS could, therefore, be a reflection of the natural history of the lesions rather than the result of radiosurgery $[20,25,26]$. Finally, cavernous malformations are dynamic lesions that may exhibit enlargement, regression, or even de novo formation [10, 27, 28]. Hence, the beneficial effect of SRS in altering the natural history of cavernoma continues to be questioned.

The risk of seizures was estimated to be $1.34 \%$ per person-year for solitary CMs and $2.48 \%$ per person-year for multiple lesions [29]. The assessment of gamma knife on the seizure control rate based on the different study design achieved the seizure free rate from 31 to $53 \%$ and decreased seizure frequency from 45 to $66 \%$, but without any treatment-related death [14, 18, 30-32]. Thus, it seems that GKRS seems to be a rational approach for improving seizure frequency associated with a cavernoma.
The outcome of radiosurgery on the intracerebral cavernoma remains controversial. One way to verify the actual effect of GKRS is by clinical observation during a longer follow-up period. In addition, one could study the effects of GKRS on quality of life and seizures in cavernoma treatment patients. In this study, we prospectively evaluated the outcomes of GKRS in cavernoma patients who were double-blind assessment by two independent neurosurgeons.

\section{Methods \\ Patient population}

From 2003 to 2018, there were 121 cases of intracranial cavernoma blindly approved by the two independent neurosurgeons excluding the in-charge neurosurgeon for the GKRS based on the patients' medical records and imaging findings at the Central Bureau of Health Insurance, Taichung, Taiwan, to determine whether GKRS was the appropriate treatment. The approval criteria was based on the consensus of Taiwan Neurosurgical Society on for GKRS including one or more of the following: recurrence of cavernoma after craniotomy, target volume less than $20 \mathrm{cc}$ or maximum diameter less than $3.5 \mathrm{~cm}$, vulnerable location for the nidus removal, severe illness inappropriate for general anesthesia, or KPS $>70$. Finally, there were 105 of 121 (86.7\%) cases approved for Gamma Knife treatment. There were 11 cases lost to follow up, and, as such, 94 (89.5\%) cases were included in this study. The treatment protocol was presented as a schematic flowchart shown in Additional file 1: Figure S1. The study was approved by the ethical committee of Taichung Veterans General Hospital on record No. CE21185B.

\section{Radiosurgical technique}

After the patient had received a local anesthetic agent, the Leksell G head frame was affixed to the head, and the patient was monitored for blood pressure, oxygenation, and electrocardiography. All patients were treated with a Leksell Gamma Knife model D (Elekta AB) by a team consisting of a neurosurgeon, neuroradiologist, radiation oncology, and medical physicist. All patients underwent GKRS with low margin dosage of 11-12 Gy prescribed to the target at the isodose line of $50-60 \%$ with radiation dose constrains with optic apparatus $<8$ Gy, brain stem $<12$ Gy, and lens $<2$ Gy. Radiosurgery dose plans, with single or multiple isocenters, were created, and the targeted margin of the cavernoma was considered to be the region characterized by mixed signal change within the T2-weighted signal-defined hemosiderin ring [33].

\section{Imaging technique}

The target lesions were typically imaged using a 1.5-T MR imaging unit (GE Medical Systems). Target localization 
was performed using T1-weighted, fast-spin-echo T2-weighted, spoiled-gradient recalled, and time-off light imaging. Additional T1-weighted, spoiled-gradient recalled, and time-of-flight sequences were also obtained after administration of gadolinium (Gd). The axial volume acquisition of $256 \times 256$ matrices was divided into 1 -mm thickness without a gap. All patients gave informed consent to receive a Gd injection in accordance with Taiwan guidelines concerning $\mathrm{Gd}$ administration during $\mathrm{MR}$ imaging examinations.

\section{Clinical follow up and assessment of Life quality}

The patients received regular follow up at 3-6 month intervals after GKRS including neurological examination and record of frequency, intensity and drug dosage in patients with a seizure history. SF-36 is a well-validated instrument for measuring quality of life (QOL) [34]. It covers 8 domains including physical function $(\mathrm{PF})$, role limitation due to a physical problem (RP), bodily pain (BP), general health $(\mathrm{GH})$, vitality, social functioning (SF), role limitation due to an emotional problem (RE), and mental health (MH). In this study, BP was specifically limited to headache and facial pain, and these were clearly described for the participants. In general, the physical component summary covered PF, RP, $\mathrm{BP}$, and $\mathrm{GH}$, whereas the mental component summary included vitality, SF, RE, and MH. Scores on the SF-36 scale range from 0 to 100 , with higher scores indicating better condition. The QOL data were collected prior to GKRS and at last out-patient follow-up. The Karnofsky Performance Score (KPS) spans from 100 to 0, where 100 is "perfect" health and 0 is death [35]. KPS was also collected by the clinical team before GKRS and at last follow up.

\section{Imaging follow-up}

All patients underwent routine MR imaging examinations 6-12 months after GKRS. More specifically, T1-weighted images were obtained with or without administration of $\mathrm{Gd}$, and T2-weighted images were obtained to evaluate whether there were any adverse treatment effects. If patients experienced new neurological deficits (increased seizure frequency, impairment sensory of motor function), they underwent additional imaging examinations at the time of newly neurological deficits to evaluate for radiologic changes associated with these clinical changes. The assessment of volume alteration was based on our previous investigation with volume enlargement by $20 \%$ defined as increase, volume reduction by $20 \%$ defined as decrease, and volume changes of less than $20 \%$ from baseline defined as stable [36].
Table 1 The characteristics of the patients $(n=94)$

\begin{tabular}{|c|c|c|}
\hline Age (years) & \multicolumn{2}{|c|}{$46.39 \pm 15.8$} \\
\hline \multicolumn{3}{|l|}{ Sex } \\
\hline Female & 55 & $(58.51 \%)$ \\
\hline Male & 39 & $(41.49 \%)$ \\
\hline \multicolumn{3}{|l|}{ Treatment indication } \\
\hline $\mathrm{ICH} /$ craniotomy & $78 / 6$ & $(82.98 \% / 6.3 \%)$ \\
\hline Seizure & 16 & $(17.02 \%)$ \\
\hline $\begin{array}{l}\text { Interval from diagnosis to GKRS } \\
\text { (months) }\end{array}$ & $4.94=$ & \\
\hline Pre-existing neurological deficits & 41 & $(43.62 \%)$ \\
\hline Familial history & 6 & $(6.38 \%)$ \\
\hline Multiple lesions & 28 & $(29.79 \%)$ \\
\hline \multicolumn{3}{|l|}{ Location } \\
\hline Brain stem & 20 & $(21.28 \%)$ \\
\hline Deep seated & 36 & $(38.30 \%)$ \\
\hline Subcortex & 38 & $(40.43 \%)$ \\
\hline Venous abnormality & 15 & $(15.96 \%)$ \\
\hline Target volume (TV) (cc) & \multicolumn{2}{|c|}{$1.93 \pm 3.45$} \\
\hline Margin dose (Gray) & \multicolumn{2}{|c|}{$11.6 \pm 1.1$} \\
\hline Physical component & \multicolumn{2}{|c|}{$131.01 \pm 34.30$} \\
\hline Mental component & \multicolumn{2}{|c|}{$118.04 \pm 48.29$} \\
\hline KPS & \multicolumn{2}{|c|}{$66.06 \pm 7.36$} \\
\hline
\end{tabular}

Continuous data were expressed mean \pm SD

Categorical data were expressed number and percentage

$\mathrm{ICH}$ intracerebral hemorrhage

\section{Statistical analysis}

Descriptive statistics were computed using standard methods to calculate mean \pm standard deviation or median values with ranges. Factors contributing to seizure frequency, imaging alteration, neurological outcome, and quality of life that were assessed by the Mann-Whitney test, Chi-Square test, and Fisher's Exact test. Cox regression analysis was used to investigate the risk factors for the new neurological deficits. Logistical regression testing was used for the assessment of the associated factors related to control of seizure and improvement in QOL. A $p$ value $<0.05$ was considered significant.

\section{Results}

Patient demographics and treatment parameters

The median age of the patients was 48 year old at the time of GKRS, and there was a male/female ratio of 55-39. The clinical diagnosis included 78 cases with hemorrhage and 16 with seizure. Forty one cases presented with preexisting neurological deficits included motor weakness of 21 , sensory impairment of 15 , and gait imbalance of 5 . 
Table 2 The characteristics of the patients stratified by treatment indication

\begin{tabular}{|c|c|c|c|}
\hline & $\mathrm{ICH}(\mathrm{n}=78)$ & Seizure $(n=16)$ & $p$ values \\
\hline Age & $47.53 \pm 15.19$ & $40.88 \pm 18.01$ & 0.146 \\
\hline \multicolumn{4}{|l|}{ Sex } \\
\hline Female & 44 & 11 & \multirow[t]{2}{*}{0.526} \\
\hline Male & 34 & 5 & \\
\hline Craniotomy & 3 & 3 & 0.06 \\
\hline Interval from diagnosis to GKRS (months) & $4.51 \pm 4.91$ & $7.0 \pm 6.18$ & 0.038 \\
\hline Pre-existing neurological deficits & 41 & 0 & $<0.001$ \\
\hline Familial Hx & 3 & 3 & 0.059 \\
\hline Multiple lesions & 21 & 7 & 0.231 \\
\hline \multicolumn{4}{|l|}{ Location } \\
\hline Brain stem & 20 & 0 & \multirow[t]{3}{*}{0.017} \\
\hline Deep seated & 31 & 5 & \\
\hline Subcortex & 27 & 11 & \\
\hline Venous abnormality & 14 & 1 & 0.454 \\
\hline Target volume (TV) & $1.89 \pm 3.64$ & $2.11 \pm 2.41$ & 0.577 \\
\hline Margin dose (Gray) & $12(11-12)$ & $12(11-12)$ & 0.392 \\
\hline Physical component & $126.12 \pm 33.60$ & $154.84 \pm 27.73$ & 0.001 \\
\hline Mental component & $345.08 \pm 77.92$ & $382.50 \pm 12.45$ & 0.001 \\
\hline KPS & $64.97 \pm 7.34$ & $71.88 \pm 4.03$ & 0.01 \\
\hline
\end{tabular}

Mann-Whitney test. ${ }^{\circ} \mathrm{Chi}$-Square test. Fisher's Exact test. ${ }^{*} p<0.05 ;{ }^{* *} p<0.01$

Continuous data were expressed mean $\pm S D$

Categorical data were expressed number and percentage

$\mathrm{ICH}$ intracerebral hemorrhage

Cavernoma locations include 20 cases in the brainstem, 36 in deep seated location and 38 in the sub-cortical region. The mean treated volume was $1.93 \pm 3.45 \mathrm{cc}$. The median margin dose was 12 Gy (11-12). The scores of pre-GKRS KPS were 66.1 \pm 7.4. Pre GKRS scores of SF-36 included general health (34.4 \pm 15.2$)$, pain (headache) $(34.5 \pm 21.2)$, social function $(25.5 \pm 16.6)$, emotional well being ( $35.6 \pm 16.9)$, energy/fatigue $(34.2 \pm 14.2)$, role limitation by emotional health $(15.6 \pm 18.1)$, role limitation by physical health $(28.7 \pm 19.1)$, physical role $(33.4 \pm 9.4)$ (Table 1). Patients' treatment indication stratified by the pre-GKRS indications of intracranial bleeding ( $\mathrm{ICH})$ and seizure are shown in Table 2.

\section{Clinical and imaging outcome}

The median follow up period was 77 months. The imaging analysis demonstrated $20(21.3 \%)$ cases of decreased nidus (Fig. 1), 67(73.4\%) stable (Fig. 2), 5 (7.3\%) with increased size (Fig. 3 and Additional file 1: Figure S2), and 2 cases with rebleeding (Additional file 1: Figure S3).

Mean post-GKRS KPS were $92.8 \pm 11.4$. Post GK scores of SF-36 included general health $(88.8 \pm 18.1)$, pain (headache) $(88.7 \pm 20.6)$, social function $(84.9 \pm 20.2)$, emotional well bening $(88.5 \pm 17.9)$, energy/fatigue $(86.2 \pm 19.3)$, role limitation by emotional health
$(80.5 \pm 24.2)$, role limitation by physical health $(87.2 \pm 24.8)$, physical role $(86.7 \pm 17.4)$. There were significant differences of life quality after GKRS in all patients (Additional file 1: Figure S3a) and also in those stratified by pre-GKRS indications of cavernoma hemorrhage and seizures (Additional file 1: Figure S3b).

Following GKRS, seven cases demonstrated new neurological deficits including 2 cases $(2.1 \%)$ with rebleeding at time point of 13 and 52 months following radiosurgery and 5 cases with deficits associated with increased nidus volume at time point of 24, 52, 80, 96, 108 , and 134 months, respectively. The associated factors for new neurological deficits were shown in Table 3 including brainstem location $(p<0.01)$, venous abnormality $(p<0.01)$, nidus increased after GKRS $(p<0.001)$, post GKRS KPS $(p<0.01)$, post GKRS physical component $(p<0.05)$, and post GKRS mental component $(p<0.01)$. The risk factors for the new neurological deficits consisted of pre-GKRS physical component $(p<0.05)$, pre-GKRS mental component $(p<0.05)$ and venous abnormality $(p<0.05)$ in Table 4 . Those patients who developed new neurological deficits also showed no improvement in life quality as illustrated in Additional file 1: Figure S4. 


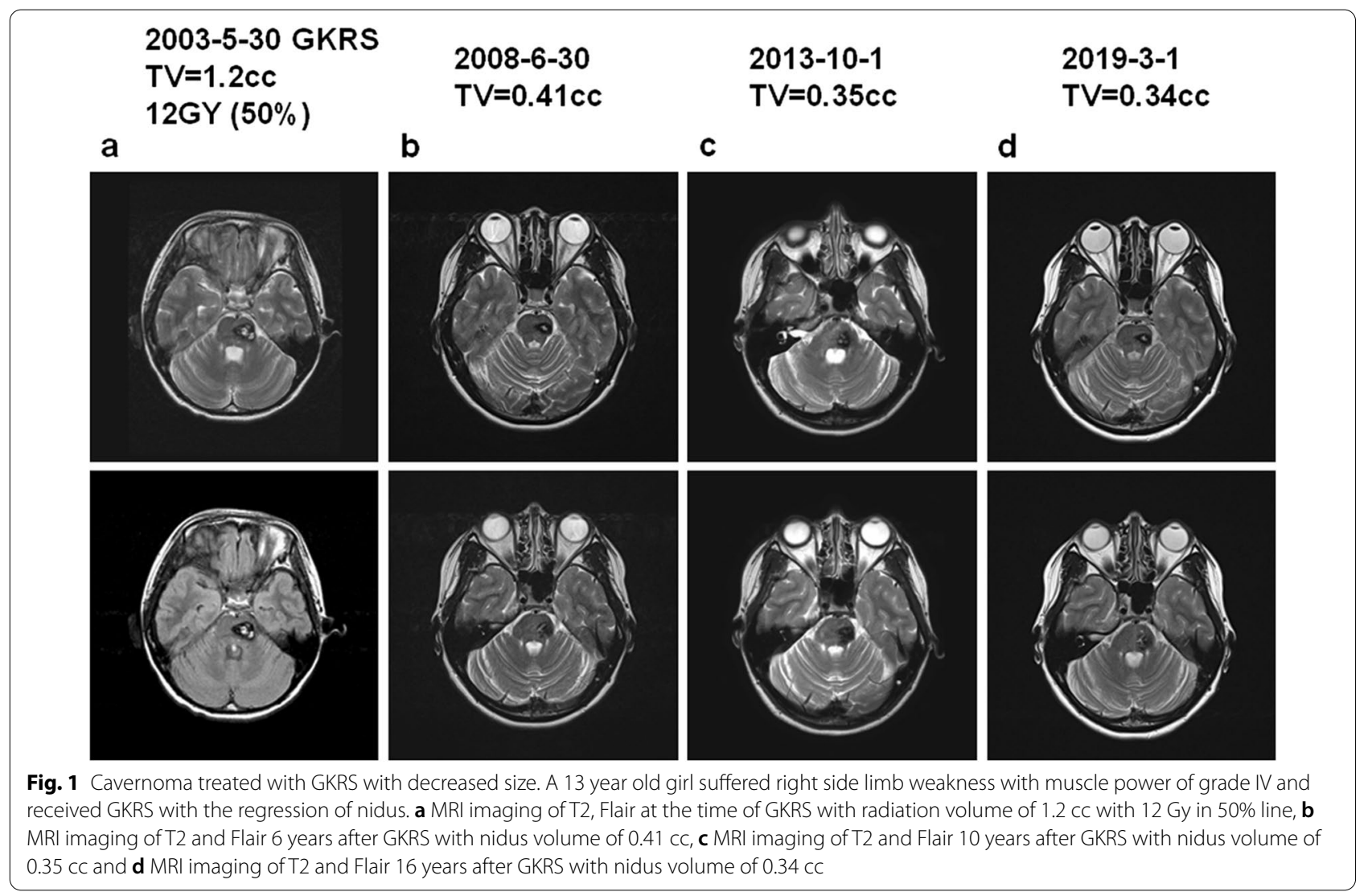

Table 3 Characteristics of the patients with new neurological deficits

\begin{tabular}{llll}
\hline & No $(\mathbf{n}=\mathbf{8 7})$ & Yes $(\mathbf{n}=\mathbf{7})$ & $\boldsymbol{p}$ value \\
\hline Age & $46.8 \pm 15.8$ & $40.8 \pm 15.8$ & 0.376 \\
Sex ration (F/M) & 1.35 & 2.25 & 0.695 \\
ICH history & 71 & 7 & 0.599 \\
Seizure history & 16 & 0 & 0.512 \\
Time to GKRS (months) & $4.95 \pm 5.23$ & $4.86 \pm 5.11$ & 0.913 \\
Pre-existing neurological deficits & $37(42.5 \%)$ & $4(57.5 \%)$ & 0.695 \\
TV (cc) & $2.0 \pm 3.56$ & $0.98 \pm 1.29$ & 0.264 \\
Familial Hx & 6 & 0 & 1 \\
Multiple lesion & 27 & 1 & 0.670 \\
Brain stem Location & $15(17.2 \%)$ & $5(71.4 \%)$ & $p<0.01$ \\
Venous abnormality & $11(12.64 \%)$ & $4(57.15 \%)$ & $p<0.01$ \\
Nidus increased post GKRS & $1(1.14 \%)$ & $4(87.1 \%)$ & $p<0.001$ \\
Post-GKRS KPS & $95.40 \pm 5.67$ & $60.0 \pm 14.14$ & $p<0.01$ \\
Post GKRS & $113.38 \pm 47.08$ & $79.3 \pm 45.79$ & $p<0.05$ \\
Physical component & & & $p<0.001$ \\
Post GKRS & $357.14 \pm 36.01$ & $129.30 \pm 95.67$ & \\
Mental component & & &
\end{tabular}

Mann-Whitney test. ' $C$ hi-Square test. Fisher's Exact test. ${ }^{*} p<0.05 ;{ }^{* *} p<0.01$

Continuous data were expressed mean $\pm S D$

Categorical data were expressed number and percentage

$\mathrm{ICH}$ intracerebral hemorrhage
In 16 cases with pre GKRS seizure, 7 cases reach the Engel I-II and 9 cases of Engel III at last follow up. There was no case of Engel IV. There were significantly different parameters for effective seizure control (Engel I/II) shown in Table 5 including post GK mental component $(p<0.004)$ and a single lesion $(p<0.05)$. In logistic regression analysis, only the single lesion showed the favorable effect $(p<0.056)$.

In the logistical regression analysis, QOL deterioration either in physical component or mental component and a decline in KPS were highly correlated to increased volume of nidus (Additional file 1: Tables S1-S3).

\section{Discussion}

The assessment of intracranial cavernoma outcomes after GKRS is confounded by the ill-defined incidence of bleeding rate, fluctuation of nidus volume, de-novo growth, and temporal hemorrhage clustering. Aside from the difficulty in the assessment of response in bleeding tendency, we found that the decreased seizure frequency and improved life quality were major contributors for the beneficial effects of GKRS on intracranial cavernoma patients. 


\section{5-2-23 GKRS $\mathrm{TV}=4.5 \mathrm{cc}, 12 \mathrm{GY}(50 \%)$}

a
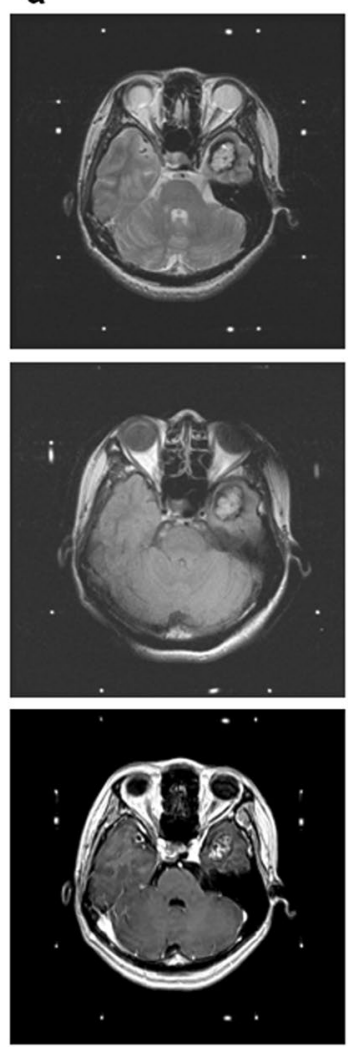

2011-2-10

$\mathrm{TV}=4.4 \mathrm{cc}$

b
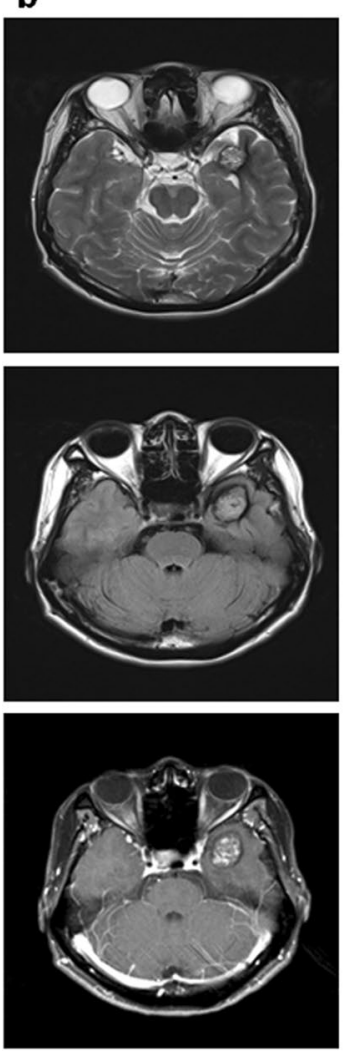

2015-12-5

$\mathrm{TV}=4.3 \mathrm{cc}$

C
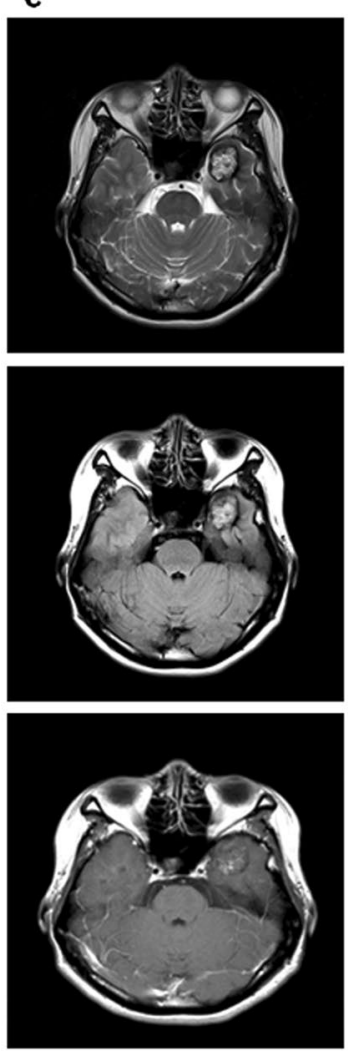

2019-8-18

$\mathrm{TV}=4.3 \mathrm{cc}$

d
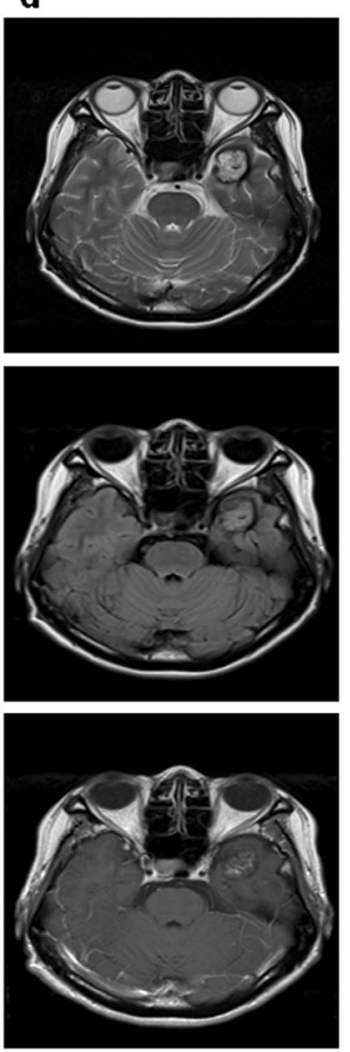

Fig. 2 Cavernoma treated with GKRS and achieving stable size. A 30 year old female presented with tonic-clonic seizure treated with Gamma Knife radiosurgery with stable size of nidus and seizure control of Engel II. a MRI imaging of T2, Flair and T1 with contrast at the time of GKRS with radiation volume of $4.5 \mathrm{cc}$ with $12 \mathrm{~Gy}$ in $50 \%$ line. b MRI imaging of T2, Flair and T1 with contrast 6 years after GKRS with nidus volume of $4.4 \mathrm{cc}$, c MRI imaging of T2, Flair and T1 with contrast 10 years after gamma knife treatment with nidus volume of 4.3 cc and $\mathbf{d}$ MRI imaging of T2, Flair and T1 with contrast 14 years after GKRS with nidus volume of $4.3 \mathrm{cc}$

There were some arguments in the assessment of a decreased cavernoma bleeding rate following GKRS. These debates included the longer latency to assess the rebleeding rate [16-18], selection and treatment biases [19], uneven allocation of the patients to operation [20], the temporal clustering of hemorrhage events [20, 25, 26], de novo CM development [21-23], and dynamic changes in $\mathrm{CM}[10,27,28]$. In this study, there were only two cases experiencing hemorrhage during the follow up at 13 and 52 months post-GKRS. Due to the low incidence of bleeding and the difficulty in defining the hemorrhage episode before GKRS, the factors subjected to analysis did demonstrate significant relationships to the development of rebleeding.

QOL improvement was a useful tool for the assessment of intracranial lesions treated by the GKRS [37, 38]. In general, the SF-36, BCM-20 and KPS were used for the assessment of life quality after GKRS. In the QOL assessment, the parameters obtained should ideally be assessed in a periodic and continuous fashion [34, 35, 37, 38]. In this study, the SF-36 and KPS data were only obtained at the time point of GKRS and the last outpatient follow up. Thus, the power of the assessment was decreased.

The effect of gamma knife on cavernoma related to seizure control was various due to the different approach in the study design. In one series, seizure control following Gamma Knife was achieved in 53\% of patients with Engel Grade I or II, and there was no treatment-related death [18]. In another large series including 291 patients enrolled, 31\% were reported to be seizure free and 35\% exhibited a decreased seizure frequency [31]. In 28 patients whose chief complaint was seizures, there was $18(64 \%)$ patients presenting a decrease in seizure frequency, but no definite grading in seizure control [32]. In 


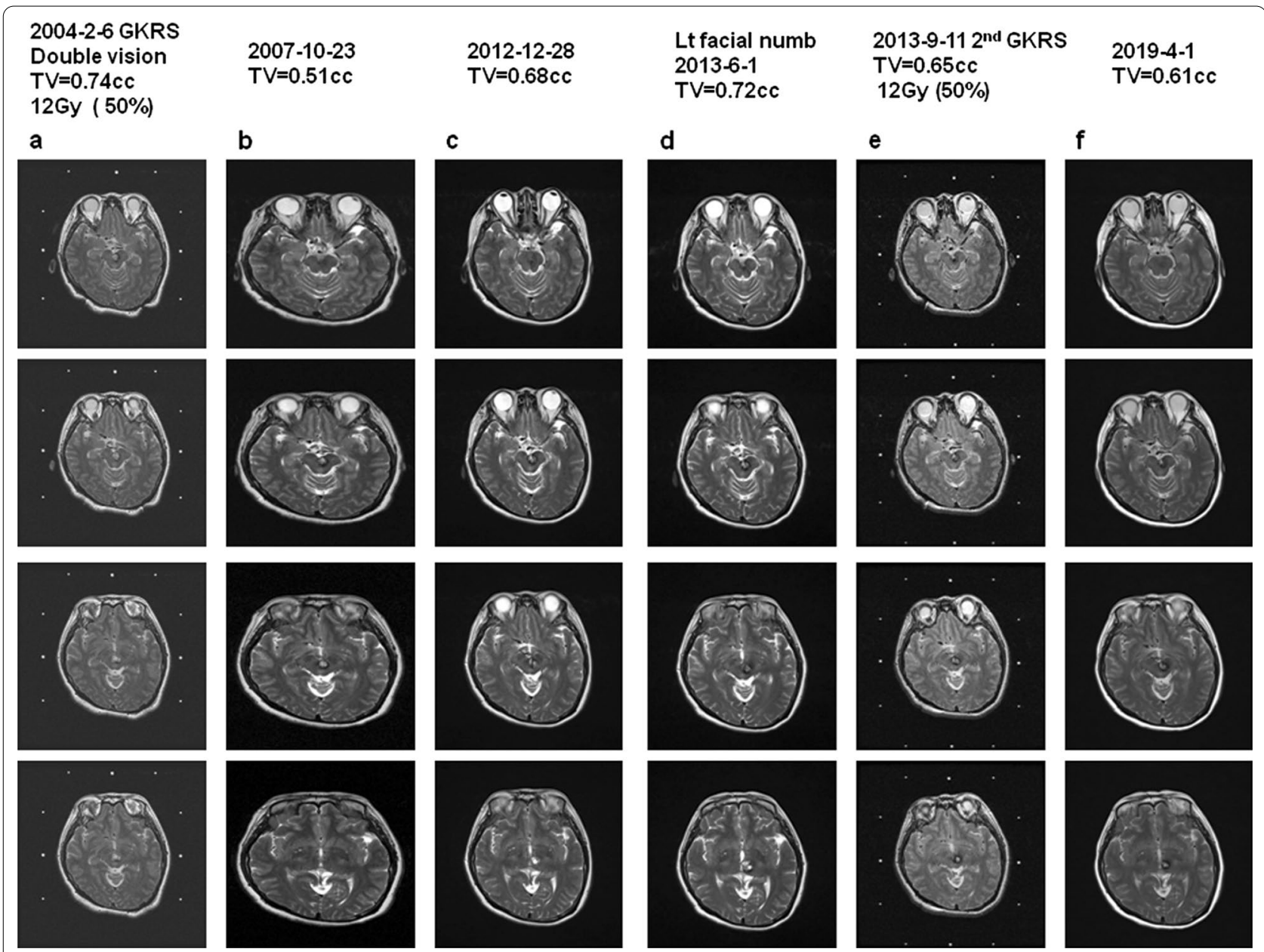

Fig. 3 Cavernoma treated with nidus progression followed by second GKRS. A 39 year old female suffered double vision treated with GKRS and underwent a second GKRS due to increased volume of the nidus with associated symptom of facial numbness a MRI imaging of T2 at the time of GKRS with treatment volume of $0.74 \mathrm{cc}$ with 12 Gy in $50 \%$ line, b MRI imaging of T2 3 years after GKRS with nidus volume of $0.51 \mathrm{cc}$, c MRI imaging of T2 weighted 8 years after GKRS with nidus volume of $0.68 \mathrm{cc}$, $\mathbf{d}$ MRI imaging of T2 9 years after GKRS with nidus volume of $0.72 \mathrm{cc}$, e MRI imaging of T2 at the time of the second GKRS with radiation volume of $0.65 \mathrm{cc}$ with 12 Gy in 50\% line and $\mathbf{f ~ M R I ~ i m a g i n g ~ o f ~ T 2 ~} 15$ years after GKRS with a nidus volume of $0.61 \mathrm{cc}$

the 65 patients, seizures were controlled without anticonvulsant medication in 81.8\% (Engel I) [14]. In 44 of 112 (39\%) patients with seizure, $45 \%$ exhibited improvement of their seizures without mentioning the grading in seizure control [30]. Thus based upon published findings, GKRS seems to be a rationale approach for improving seizure frequency associated with a cavernoma.

There is still a debate concerning the optimal radiosurgical dose for cavernoma treatment to achieve a beneficial response and minimize side effects. Doses exceeding 15-16 Gy have previously demonstrated significant radiation edema [32, 39]. In lesions located at in the brainstem even with a margin dose of $13 \mathrm{~Gy}$, there is substantial increase in radiation induced complication [40], and it seem that $13 \mathrm{~Gy}$ is the upper margin dose without significant risk of adverse effects for radiosurgically treated cavernomas [33]. In some anecdotal report, a margin dose of as low as 10 Gy has significant effect in cavernoma shrinkage [41]. In this study, a margin dosage of 11-12 Gy afforded recognizable nidus shrinkage or stability without appreciable adverse effect. Thus the optimal dose and threshold for radiation-related complication for CMs have not been defined until now. It seems that there is a need to explore the issue further particularly for specific sites such as the brainstem.

The effects of GKRS on intracerebral cavernoma are confounded by many factors which are difficult to control, and, therefore, the role of GKRS for cavernomas remains controversial. The only way to verify a beneficial effect of the treatment is to demonstrate no 
Table 4 Risk factors for the new neurological deficits

\begin{tabular}{|c|c|c|c|c|}
\hline & Simple model & & Multiple model & \\
\hline & $\mathrm{HR}(95 \% \mathrm{Cl})$ & $p$ value & $\mathrm{HR}(95 \% \mathrm{Cl})$ & $p$ value \\
\hline Age & $1.00(0.95-1.04)$ & 0.909 & & \\
\hline \multicolumn{5}{|l|}{ Sex } \\
\hline Female & ref & & & \\
\hline Male & $0.73(0.13-4.07)$ & 0.715 & & \\
\hline Time from diagnosis to GK (months) & $0.95(0.78-1.14)$ & 0.565 & & \\
\hline Neurological deficits & $3.29(0.58-18.61)$ & 0.179 & & \\
\hline $\mathrm{TV}(\mathrm{cc})$ & $0.91(0.58-1.43)$ & 0.693 & & \\
\hline Margin dose (Gy) & $1.33(0.67-2.63)$ & 0.419 & & \\
\hline Multiple lesions at GK & $0.63(0.07-5.62)$ & 0.678 & & \\
\hline Physical component & $0.95(0.92-0.99)$ & 0.019 & $0.97(0.92-1.01)$ & 0.128 \\
\hline Mental component & $0.97(0.95-0.996)$ & 0.019 & $0.98(0.96-1.01)$ & 0.125 \\
\hline \multicolumn{5}{|l|}{ Location } \\
\hline Brain stem + deep seated & ref & & & \\
\hline Subcortical & $0.33(0.04-2.89)$ & 0.319 & & \\
\hline Venous abnormality & $5.36(1.02-28.06)$ & 0.047 & $3.03(0.59-15.46)$ & 0.183 \\
\hline
\end{tabular}

Cox regression. * $p<0.05 ;{ }^{* *} p<0.01$

$H R$ hazard ratio

increased annual risk of re-bleeding and no appreciable complications from the treatment itself. Based on the above assumption, we applied a low margin dose of 11-12 Gy to treat the cavernoma and found that most

Table 5 Characteristics of the patients in the seizure control

\begin{tabular}{|c|c|c|c|}
\hline & Engel $1-2(n=7)$ & Engel $3(n=9)$ & $p$ value \\
\hline Age & $49.86 \pm 20.23$ & $33.89 \pm 13.27$ & 0.119 \\
\hline $\operatorname{Sex}(F / M)$ & $5 / 2$ & $6 / 3$ & 1 \\
\hline History of craniotomy & 1 & 2 & 1 \\
\hline $\begin{array}{l}\text { Interval from diagnosis } \\
\text { to GKRS }\end{array}$ & $8.00 \pm 8.77$ & $6.22 \pm 3.49$ & 0.898 \\
\hline $\begin{array}{l}\text { Physical component at } \\
\text { GKRS }\end{array}$ & $162.14 \pm 28.15$ & $149.17 \pm 27.64$ & 0.303 \\
\hline $\begin{array}{l}\text { Mental component at } \\
\text { GKRS }\end{array}$ & $384.29 \pm 13.28$ & $381.11 \pm 12.38$ & 0.639 \\
\hline KPS at GKRS & $72.86 \pm 4.88$ & $71.11 \pm 3.33$ & 0.55 \\
\hline $\begin{array}{l}\text { Physical component after } \\
\text { GKRS }\end{array}$ & $141.27 \pm 18.94$ & $142.76 \pm 30.83$ & 0.938 \\
\hline $\begin{array}{l}\text { Mental component after } \\
\text { GKRS }\end{array}$ & $397.29 \pm 3.86$ & $377.59 \pm 15.43$ & 0.004 \\
\hline KPS after GKRS & $98.57 \pm 3.78$ & $97.78 \pm 4.41$ & 1 \\
\hline TV $(c c)$ & $1.83 \pm 2.04$ & $2.33 \pm 2.76$ & 0.123 \\
\hline Multiple lesions & 1 & 6 & 0.04 \\
\hline $\begin{array}{l}\text { Location (subcortical } \\
\text { region) }\end{array}$ & 3 & 8 & 0.106 \\
\hline $\begin{array}{l}\text { Post GKRS volume } \\
\text { (increase) }\end{array}$ & 0 & 1 & 0.652 \\
\hline
\end{tabular}

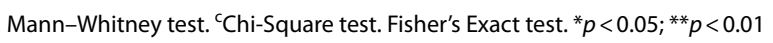

Continuous data were expressed mean \pm SD

Categorical data were expressed number and percentage patients demonstrated decreased seizure frequency, stabilization of the cavernoma, and improvement in QOL. Also, there were no definite adverse effects associated with GKRS. Therefore, a low margin dose of 11-12 Gy in the treatment of cavernoma seems to be a reasonable approach.

\section{Conclusion}

Low margin dose GKRS for intracerebral cavernoma seems to be a reasonable approach which reduces seizure frequency and improves quality of life in the majority of patients. This treatment appears to be without appreciable risk of adverse radiation effects.

\begin{abstract}
Abbreviations
GKRS: Gamma Knife Radiosurgery; SRS: Stereotactic radiosurgery; TV: Target volume; Gy: Gray; MRI: Magnetic resonance imaging; Gd: Gadolinium; CM: Intracerebral cavernoma; ICH: Intracranial bleeding; KPS: Karnofsky performance score; QOL: Quality of life; PF: Physical function; RP: Role limitation due to a physical problem; BP: Bodily pain; GH: General health; SF: Social functioning; RE: Role limitation due to an emotional problem; MH: Mental health $(\mathrm{MH})$.
\end{abstract}

\section{Supplementary Information}

The online version contains supplementary material available at https://doi. org/10.1186/s13014-021-01885-4.

Additional file 1. Figure $\mathrm{S} 1$ : The treatment protocol was presented as a schematic flowchart. Figure S2: Cavernoma treated with nidus progression followed by second GKRS and craniotomy. A 29 year old female suffered facial numbness treated with GKRS and received a second GKRS due to increased volume of nidus with the recurrent symptom of facial 
numbness. The patient underwent a craniotomy due to intractable facial numbness and the surgery was associated with postoperative neurological deficits (a) MRI imaging of T2 at the time of GKRS with radiation volume of $2.4 \mathrm{cc}$ with $12 \mathrm{~Gy}$ in $50 \%$ line (b) MRl imaging of T2 one year after GKRS with nidus volume of $0.5 \mathrm{cc}$ (c) MRl imaging of T2 weighted 2 years after GKRS with nidus volume of $2.0 \mathrm{cc}$ (d) MRI imaging of $\mathrm{T} 2$ at the time of second GKRS with radiation volume of $2.1 \mathrm{cc}$ with 12 Gy in $50 \%$ line (e) MRI imaging of T2 9 years after a second GKRS and craniotomy with nidus volume of 1.1cc. Figure S3: Cavernoma treated with GKRS and demonstrating nidus progression and hemorrhage. A 41 year old female suffered facial numbness treated with GKRS and suffered the repeated bleedings (a) MRl imaging of T2, Flair and T1 with contrast at the time of gamma knife treatment with radiation volume of $0.1 \mathrm{cc}$ with $12 \mathrm{~Gy}$ in $50 \%$ line (b) MRl imaging of T2, Flair , and T1 with contrast three year after GKRS with nidus volume of $0.21 \mathrm{cc}$ (c) CT imaging 5 years after GKRS with intracerebral hemorrhage (d) MRI imaging of T2, Flair , and T1 with contrast 5 years after GKRS with a nidus volume of $0.023 \mathrm{cc}$ (e) MRI imaging of T2, FLAIR, and T1 with contrast 11 years after GKRS with a nidus volume of $0.021 \mathrm{cc}$. Figure S4: Plot of life quality before and after GKRS. (a) Plot of life quality including SF-36 and KPS before and after GKRS. (b) Plot of life quality of SF-36 and KPS stratified by the etiologies of intracerebral hemorrhage and seizure. ${ }^{*}: p<0.05 ; * *: p<0.01$. Figure S5: Plots of life quality of SF-36 and KPS in the patients either with or without development of new neurological deficits. ${ }^{*}: \mathrm{p}<0.01$. Table $\mathrm{S1}$ : The associated factors contributing to the improvement of physical component. Table S2: The associated factors contributing to improvement in mental component. Table S3: The associated factors contributing to the improvement in KPS.

\section{Acknowledgements}

The authors would like to thanks all assistant and Biostatistics Task Force of Taichung Veterans General Hospital for their kind assistances in the manuscript preparation and statistical analysis.

\section{Authors' contributions}

SCC and SML collected the data and wrote the manuscript. YMY, YWC and CYJ collected the data of imaging and clinical data for analysis. CYJ and SML helped in statistical analysis. SJ helped to design this study and edit the manuscript. PHC conducted the study design and collected the data and edited the manuscript.

\section{Funding}

The funding (TCVGH-1 107306C and TCVGH-PU1 1068106) was received from Taichung Veterans General Hospital, Taichung, Taiwan.

\section{Availability of data and material}

All data generated or analyzed during this study are included in this published article and its additional files.

\section{Declarations}

\section{Ethical approval and consent to participate}

Approval by ethical committee of Taichung Veterans General Hospital is on record No. CE21185B.

\section{Consent for publication}

Not applicable.

\section{Competing interests}

There was no conflict of interest.

\footnotetext{
Author details

'Department of Neurosurgery, Taichung Veterans General Hospital, Taichung, Taiwan. ${ }^{2}$ Basic Medical Education Center, Central Taiwan University of Science and Technology, Taichung, Taiwan. ${ }^{3}$ Department of Radiation Oncology, Taichung Veterans General Hospital, Taichung, Taiwan. ${ }^{4}$ Institute of Biomedical Science, National Chung-Hsin University, Taichung, Taiwan. ${ }^{5}$ College of Humanities and Social Sciences, Providence University, Taichung, Taiwan. ${ }^{6}$ Department of Neurosurgery, University of Virginia, Charlottesville, VA, USA.
}

${ }^{7}$ Department of Medical Research and Neurosurgery, Taichung Veterans General Hospital, 1650 Taiwan Boulevard Sec.4, Taichung 40705, Taiwan. ${ }^{8}$ Rong Hsing Research Center for Translational Medicine, National Chung Hsing University, Taichung, Taiwan.

Received: 2 June 2021 Accepted: 14 August 2021

Published online: 28 August 2021

\section{References}

1. De Curling O, Kelly DL, Elster AD, Craven TE. An analysis of the natural history of cavernous angiomas. J Neurosurg. 1991;75:702-8.

2. Kim DS, Park YG, Choi JU, Chung SS, Lee KC. An analysis of the natural history of cavernous malformations. Surg Neurol. 1997;48:9-17.

3. Robinson JR, Awad IA, Little JR. Natural history of the cavernous angioma. J Neurosurg. 1991;75:709-14.

4. Sarwar M, McCormick WF. Intracerebral venous angioma. Case report and review. Archiv Neurol. 1978;35:323-5.

5. Aiba T, Tanaka R, Koike T, Kameyama S, Takeda N, Komata T. Natural history of intracranial cavernous malformations. J Neurosurg. 1995;83:56-9.

6. Al-Shahi Salman R, Berg MJ, Morrison L, Awad IA. Hemorrhage from cavernous malformations of the brain: definition and reporting standards. Angioma Alliance Scientific Advisory Board. Stroke. 2008;39:3222-30.

7. Kondziolka D, Lunsford LD, Kestle JR. The natural history of cerebral cavernous malformations. J Neurosurg. 1995;83:820-4.

8. Porter PJ, Willinsky RA, Harper W, Wallace MC. Cerebral cavernous malformations: natural history and prognosis after clinical deterioration with or without hemorrhage. J Neurosurg. 1997;87:190-7.

9. Robinson JR Jr, Awad IA, Magdinec M, Paranandi L. Factors predisposing to clinical disability in patients with cavernous malformations of the brain. Neurosurgery. 1993;32:730-5.

10. Zabramski JM, Wascher TM, Spetzler RF, Johnson B, Golfinos J, Drayer BP, et al. The natural history of familial cavernous malformations: results of an ongoing study. J Neurosurg. 1994;80:422-32.

11. Porter RW, Detwiler PW, Spetzler RF, Lawton MT, Baskin JJ, Derksen PT, et al. Cavernous malformations of the brainstem: experience with 100 patients. J Neurosurg. 1999;90:50-8.

12. Attar A, Ugur HC, Savas A, Yüceer N, Egemen N. Surgical treatment of intracranial cavernous angiomas. J Clin Neurosci Off J Neurosurg Soc Australas. 2001;8:235-9.

13. Huang YC, Tseng CK, Chang CN, Wei KC, Liao CC, Hsu PW. LINAC radiosurgery for intracranial cavernous malformation: 10-year experience. Clin Neurol Neurosurg. 2006;108:750-6.

14. Kim MS, Pyo SY, Jeong YG, Lee SI, Jung YT, Sim JH. Gamma knife surgery for intracranial cavernous hemangioma. J Neurosurg. 2005;102(Suppl):102-6.

15. Régis J, Bartolomei F, Kida Y, Kobayashi T, Vladyka V, Liscàk R, et al. Radiosurgery for epilepsy associated with cavernous malformation: retrospective study in 49 patients. Neurosurgery. 2000;47:1091-7.

16. Gross BA, Batjer HH, Awad IA, Bendok BR. Brainstem cavernous malformations. Neurosurgery. 2009;64:E805-18.

17. Hasegawa T, Mclnerney J, Kondziolka D, Lee JY, Flickinger JC, Lunsford LD. Long-term results after stereotactic radiosurgery for patients with cavernous malformations. Neurosurgery. 2002;50:1190-7.

18. Liu KD, Chung WY, Wu HM, Shiau CY, Wang LW, Guo WY, et al. Gamma knife surgery for cavernous hemangiomas: an analysis of 125 patients. J Neurosurg. 2005;102(Suppl):81-6.

19. Abla AA, Lekovic GP, Turner JD, de Oliveira JG, Porter R, Spetzler RF. Advances in the treatment and outcome of brainstem cavernous malformation surgery: a single-center case series of 300 surgically treated patients. Neurosurgery. 2011;68:403-14.

20. Barker FG 2nd, Amin-Hanjani S, Butler WE, Lyons S, Ojemann RG, Chapman PH, et al. Temporal clustering of hemorrhages from untreated cavernous malformations of the central nervous system. Neurosurgery. 2001;49:15-24.

21. Nagy G, Razak A, Rowe JG, Hodgson TJ, Coley SC, Radatz MW, et al. Stereotactic radiosurgery for deep-seated cavernous malformations: a move toward more active, early intervention. Clinical article. J Neurosurg. 2010;113:691-9. 
22. Nimjee SM, Powers CJ, Bulsara KR. Review of the literature on de novo formation of cavernous malformations of the central nervous system after radiation therapy. Neurosurg Focus. 2006;21:e4.

23. Yeon JY, Suh YL, Kim JH, Lee Jl. Development of de novo cavernous hemangioma after radiosurgery for cavernous hemangioma. J Korean Neurosurg Soc. 2010;48:532-3.

24. Duffau H, Capelle L, Sichez JP, Faillot T, Bitar A, Arthuis F, et al. Early radiologically proven rebleeding from intracranial cavernous angiomas: report of 6 cases and review of the literature. Acta Neurochir. 1997:139:914-22.

25. Gross BA, Batjer HH, Awad IA, Bendok BR. Cavernous malformations of the basal ganglia and thalamus. Neurosurgery. 2009;65:7-18.

26. Kim DG, Choe WJ, Paek SH, Chung HT, Kim IH, Han DH. Radiosurgery of intracranial cavernous malformations. Acta Neurochir. 2002;144:869-78.

27. Clatterbuck RE, Moriarity JL, Elmaci I, Lee RR, Breiter SN, Rigamonti D. Dynamic nature of cavernous malformations: a prospective magnetic resonance imaging study with volumetric analysis. J Neurosurg. 2000;93:981-6.

28. Raychaudhuri R, Batjer HH, Awad IA. Intracranial cavernous angioma: a practical review of clinical and biological aspects. Surg Neurol. 2005;63:319-28.

29. Pham M, Gross BA, Bendok BR, Awad IA, Batjer HH. Radiosurgery for angiographically occult vascular malformations. Neurosurg Focus. 2009;26:E16.

30. Liscák R, Vladyka V, Simonová G, Vymazal J, Novotny J Jr. Gamma knife surgery of brain cavernous hemangiomas. J Neurosurg. 2005;102(Suppl):207-13.

31. Lunsford LD, Niranjan A, Kano H, Kondziolka D. The technical evolution of gamma knife radiosurgery for arteriovenous malformations. Prog Neurol Surg. 2013;27:22-34.

32. Zhang N, Pan L, Wang BJ, Wang EM, Dai JZ, Cai PW. Gamma knife radiosurgery for cavernous hemangiomas. J Neurosurg. 2000;93(Suppl 3):74-7.

33. Kim BS, Yeon JY, Kim JS, Hong SC, Lee Jl. Gamma knife radiosurgery of the symptomatic brain stem cavernous angioma with low marginal dose. Clin Neurol Neurosurg. 2014;126:110-4.
34. Motamed N, Ayatollahi AR, Zare N, Sadeghi-Hassanabadi A. Validity and reliability of the Persian translation of the SF-36 version 2 questionnaire. Eastern Mediterr Health J. 2005;11:349-57.

35. Mendelsohn J. Blockade of receptors for growth factors: an anticancer therapy-the fourth annual Joseph $\mathrm{H}$ Burchenal American Association of Cancer Research Clinical Research Award Lecture. Clin Cancer Res Off J Am Assoc Cancer Res. 2000:6:747-53.

36. Pan SY, Liu SA, Sun MH, Tsou HK, Lee SD, Chen YJ, et al. Outcome of hearing preservation related to tumor morphologic analysis in acoustic neuromas treated by gamma knife radiosurgery. Radiat Oncol (Lond Engl). 2017;12:134.

37. Pan HC, Sheehan J, Huang CF, Sheu ML, Yang DY, Chiu WT. Quality-of-life outcomes after Gamma Knife surgery for trigeminal neuralgia. J Neurosurg. 2010;113(Suppl):191-8.

38. Pan HC, Sun MH, Chen CC, Chen CJ, Lee CH, Sheehan J. Neuroimaging and quality-of-life outcomes in patients with brain metastasis and peritumoral edema who undergo Gamma Knife surgery. J Neurosurg. 2008;109(Suppl):90-8.

39. Liscák R, Vladyka V, Simonová G, Vymazal J, Novotny J Jr. Gamma knife radiosurgery of the brain stem cavernomas. Minim Invasive Neurosurg MIN. 2000;43:201-7.

40. Amin-Hanjani S, Ogilvy CS, Candia GJ, Lyons S, Chapman PH. Stereotactic radiosurgery for cavernous malformations: Kjellberg's experience with proton beam therapy in 98 cases at the Harvard Cyclotron. Neurosurgery. 1998;42:1229-36.

41. Ivanov P, Chernov M, Hayashi M, Nakaya K, Izawa M, Murata N, et al. Low-dose gamma knife radiosurgery for cavernous sinus hemangioma: report of 3 cases and literature review. Minim Invasive Neurosurg MIN. 2008;51:140-6.

\section{Publisher's Note}

Springer Nature remains neutral with regard to jurisdictional claims in published maps and institutional affiliations.
Ready to submit your research? Choose BMC and benefit from:

- fast, convenient online submission

- thorough peer review by experienced researchers in your field

- rapid publication on acceptance

- support for research data, including large and complex data types

- gold Open Access which fosters wider collaboration and increased citations

- maximum visibility for your research: over $100 \mathrm{M}$ website views per year

At $\mathrm{BMC}$, research is always in progress.

Learn more biomedcentral.com/submissions 